\title{
The MaCWAVE program to study gravity wave influences on the polar mesosphere
}

\author{
R. A. Goldberg ${ }^{1}$, D. C. Fritts ${ }^{2}$, F. J. Schmidlin ${ }^{3}$, B. P. Williams ${ }^{2}$, C. L. Croskey ${ }^{4}$, J. D. Mitchell ${ }^{4}$, M. Friedrich ${ }^{5}$, \\ J. M. Russell III ${ }^{6}$, U. Blum ${ }^{7}$, and K. H. Fricke ${ }^{8}$ \\ ${ }^{1}$ NASA/Goddard Space Flight Center, Code 612.3, Greenbelt, MD 20771, USA \\ ${ }^{2}$ NorthWest Research Assoc., Colorado Research Associates Div., Boulder, CO 80301, USA \\ ${ }^{3}$ NASA/Goddard Space Flight Center, Wallops Flight Facility, Code 972, Wallops Island, VA 23337, USA \\ ${ }^{4}$ Pennsylvania State University, Department of Electrical Engineering, University Park, PA 16802, USA \\ ${ }^{5}$ Graz University of Technology, A-8010 Graz, Austria \\ ${ }^{6}$ Hampton University, Center for Atmospheric Research, Hampton, VA 23681, USA \\ ${ }^{7}$ Forsvarets forskningsinstitutt, Postboks 25, NO-2027 Kjeller, Norway \\ ${ }^{8}$ Physikalisches Institut der Universität Bonn, D-53115 Bonn, Germany
}

Received: 30 September 2005 - Revised: 3 March 2006 - Accepted: 10 May 2006 - Published: 3 July 2006

Part of Special Issue "MaCWAVE: a rocket-lidar-radar program to study the polar mesosphere during summer and winter"

\begin{abstract}
MaCWAVE (Mountain and Convective Waves Ascending VErtically) was a highly coordinated rocket, ground-based, and satellite program designed to address gravity wave forcing of the mesosphere and lower thermosphere (MLT). The MaCWAVE program was conducted at the Norwegian Andøya Rocket Range (ARR, 69.3 ${ }^{\circ} \mathrm{N}$ ) in July 2002, and continued at the Swedish Rocket Range (Esrange, $67.9^{\circ} \mathrm{N}$ ) during January 2003. Correlative instrumentation included the ALOMAR MF and MST radars and RMR and $\mathrm{Na}$ lidars, Esrange MST and meteor radars and RMR lidar, radiosondes, and TIMED (Thermosphere Ionosphere Mesosphere Energetics and Dynamics) satellite measurements of thermal structures. The data have been used to define both the mean fields and the wave field structures and turbulence generation leading to forcing of the large-scale flow. In summer, launch sequences coupled with groundbased measurements at ARR addressed the forcing of the summer mesopause environment by anticipated convective and shear generated gravity waves. These motions were measured with two 12-h rocket sequences, each involving one Terrier-Orion payload accompanied by a mix of MET rockets, all at ARR in Norway. The MET rockets were used to define the temperature and wind structure of the stratosphere and mesosphere. The Terrier-Orions were designed to measure small-scale plasma fluctuations and turbulence that might be induced by wave breaking in the mesosphere. For the summer series, three European MIDAS (Middle Atmosphere Dynamics and Structure) rockets were also launched from ARR in coordination with the MaCWAVE
\end{abstract}

Correspondence to: R. A. Goldberg

(richard.a.goldberg@nasa.gov) payloads. These were designed to measure plasma and neutral turbulence within the MLT. The summer program exhibited a number of indications of significant departures of the mean wind and temperature structures from "normal" polar summer conditions, including an unusually warm mesopause and a slowing of the formation of polar mesospheric summer echoes (PMSE) and noctilucent clouds (NLC). This was suggested to be due to enhanced planetary wave activity in the Southern Hemisphere and a surprising degree of interhemispheric coupling. The winter program was designed to study the upward propagation and penetration of mountain waves from northern Scandinavia into the MLT at a site favored for such penetration. As the major response was expected to be downstream (east) of Norway, these motions were measured with similar rocket sequences to those used in the summer campaign, but this time at Esrange. However, a major polar stratospheric warming just prior to the rocket launch window induced small or reversed stratospheric zonal winds, which prevented mountain wave penetration into the mesosphere. Instead, mountain waves encountered critical levels at lower altitudes and the observed wave structure in the mesosphere originated from other sources. For example, a large-amplitude semidiurnal tide was observed in the mesosphere on 28 and 29 January, and appears to have contributed to significant instability and small-scale structures at higher altitudes. The resulting energy deposition was found to be competitive with summertime values. Hence, our MaCWAVE measurements as a whole are the first to characterize influences in the MLT region of planetary wave activity and related stratospheric warmings during both winter and summer.

Published by Copernicus GmbH on behalf of the European Geosciences Union. 
Keywords. Atmospheric composition and structure (Pressure, density and temperature) - Meteorology and atmospheric dynamics (Waves and tides; Middle atmosphere dynamics)

\section{Introduction}

Observational and theoretical studies during the last few decades have revealed a rich spectrum of dynamical, radiative, chemical, and photochemical processes that act (and interact) to control the circulation, thermal structure, and composition of the mesosphere and lower thermosphere (MLT). These efforts have defined qualitatively the mean state, the broad character of the motion spectrum, and some of the causes and effects of variability in these regions (Holton, 1982; Garcia and Solomon, 1985). Yet the energy inputs, their source distributions and temporal character, the processes coupling various regions, and the detailed responses to periodic and secular forcings are poorly understood at this time. Seasonal differences are especially dramatic at polar latitudes, where gravity waves are believed to provide the majority of the mean forcing and variability and to account for the seasonal differences in mean structure (see Fritts and Alexander, 2003, for a recent review of these various processes and effects).

The MLT is influenced from above and below in a variety of ways. Extreme ultraviolet solar radiation and particle fluxes account primarily for the mean thermal forcing and structure in the lower thermosphere. Ion drag and Joule heating also contribute to the large-scale structure at thermospheric altitudes. However, the major dynamical forcing and the sources of spatial and temporal variability on multiple scales in the MLT likely accompany the upward propagation and dissipation of wave motions arising from sources within the troposphere and stratosphere. This occurs because wave amplitudes grow approximately exponentially with height due to the decrease in the mean density, and thus attain very large values (and large influences) in the MLT. Tidal and planetary wave motions are excited primarily through the absorption of solar radiation by water vapor and ozone, through latent heat release due to deep tropical convection, topography, and from differential land/sea solar heating. In contrast, gravity waves are excited preferentially by orography, frontal processes, convection, and jet streams.

At lower altitudes, gravity wave and tidal influences are generally less than those of the planetary-wave motions. In the MLT, in contrast, gravity wave and tidal influences are much more dramatic. Their influences include, among others, interactions, filtering, and dissipation that result in strong local body forces (Reid et al., 1988; Fritts and Yuan, 1989), modulation of wave motions at lower and higher frequencies (Fritts and Vincent, 1987; Wang and Fritts, 1990; Forbes et al., 1991; Lu and Fritts, 1993; McLandress and Ward,
1994; Broutman et al., 1997; Eckermann, 1997; Norton and Thuburn, 1996; Mayr et al., 1998; Meyer, 1999a, 1999b), closure of the mesospheric jets in the summer and winter hemispheres (Dunkerton, 1982; Holton, 1982, 1983; Garcia and Solomon, 1985), and a strong vertical and meridional circulation from the summer to the winter hemisphere near the mesopause that accounts for the cold summer mesopause and warm winter mesopause (Nastrom et al., 1982; Fritts and Yuan, 1989; Garcia, 1989; Fritts and Luo, 1995; Fritts and Alexander, 2003). For these reasons, the mesopause is a site of intense current scientific interest.

The major influence of these motions in the MLT is exerted through the vertical transport of horizontal momentum by gravity waves with high intrinsic frequencies (Fritts and Vincent, 1987). This momentum flux and its vertical convergence control the mean vertical and meridional circulation, and thus the thermal field at these heights, via a process known as "downward control" (McIntyre, 1989; Haynes et al., 1991; Garcia and Boville, 1994). These processes are poorly understood at present, but are important drivers of the middle atmospheric circulation, structure, and large-scale variability that can be addressed with appropriate and comprehensive high-latitude in situ and ground-based measurements. Indeed, our understanding (and parameterizations) of mountain wave penetration into the MLT in winter is severely lacking, while virtually nothing is known of the sources and propagation of waves that influence the summer mesopause.

These factors were the drivers for our comprehensive MaCWAVE (Mountain and Convective Waves Ascending VErtically) summer and winter rocket and ground-based measurement programs that are the subject of this special issue. The summer MaCWAVE/MIDAS (Middle Atmosphere Dynamics and Structure) launch sequences were performed at Andøya Rocket Range (ARR, 69.3 ${ }^{\circ} \mathrm{N}, 16.0^{\circ} \mathrm{E}$ ) and coordinated with ground-based measurements at the ALOMAR Observatory. These addressed the forcing of the summer mesopause environment by anticipated convective and shear generated gravity waves. A sequence of papers in Geophysical Research Letters (e.g. Goldberg and Fritts, 2004; Goldberg et al., 2004) described the initial results from this program.

The winter MaCWAVE rocket program was performed at Esrange $\left(67.9^{\circ} \mathrm{N}, 21.0^{\circ} \mathrm{E}\right)$ to measure the structure and propagation of mountain waves that often arise in the lee of the Scandinavian mountains and which are expected to penetrate, under suitable conditions, to very high altitudes. The winter program employed radars, lidars, and balloons at both Esrange and ARR to characterize both upstream and downstream conditions. However, a stratospheric warming just prior to the rocket launch window induced small or reversed stratospheric zonal winds, which prevented mountain wave penetration to higher altitudes. This caused a refocusing of our measurement goals and analyses, but resulted in a very interesting data set and a number of useful scientific results. These results represent some of the major contributions 
to this MaCWAVE special issue. This paper provides an overview of the overall MaCWAVE program, including both summer and winter measurements, in order to introduce the reader to those papers that follow.

There are nine papers, including this overview, appearing in this MaCWAVE special section. These papers span a wide range of topics from the general circulation of the atmosphere and inter-hemispheric coupling during Northern Hemisphere summer in 2002 to small-scale neutral and plasma dynamics and layering under summer and winter conditions. This overview provides a general introduction to all of the MaCWAVE results obtained to date, including a summary of results of our previous special issue in Geophysical Research Letters focusing on the summer MaCWAVE/MIDAS measurement program. Successive papers are organized according to the spatial and temporal scales of the processes addressed, from larger to smaller. The paper by Becker and Fritts (2006) examines the influences of inter-hemispheric coupling arising from anomalously strong planetary wave activity in the southern winter hemisphere on the summer polar MLT circulation and thermal structure. Blum et al. (2006) describe the large-scale environment, including stratospheric warming responses, accompanying the winter MaCWAVE measurement program in January and February 2003. Williams et al. (2006a) and Wang et al. (2006) examine, respectively, gravity wave responses and instabilities accompanying large-amplitude tidal motions and propagation into a weak or reversed zonal flow due to the stratospheric warming occurring during our winter measurement program. Nielson et al. (2006) analyze the character of small-scale gravity wave and instability structures near the mesopause in winter. Finally, Kirkwood et al. (2006), Williams et al. (2006b), and Croskey et al. (2006) examine the microphysics underlying polar mesosphere winter echoes, correlated sporadic sodium and $\mathrm{E}$ layers, and plasma structures at small spatial scales.

\section{MaCWAVE payload description and logistics}

Figure 1 is an artist's conception designed to describe the summer 2002 program at ARR in Norway. The plan in summer was to define the wave field as quantitatively as possible in order to assess possible sources, propagation, consequences of instability, transport of energy and momentum, and wave-mean flow interactions. To accomplish this, two sequences of rocket and balloon payloads were launched from ARR in early July 2002. Meteorological falling spheres (FS) were used to define the large-scale structure and dynamics of the stratosphere, mesosphere, and lower thermosphere. The MaCWAVE payloads were designed to observe small-scale structure in the local plasma, with the assumption that these would indicate turbulence structures in the neutral atmosphere. The MaCWAVE payloads were coordinated with three MIDAS payloads (Blix et al., 2003), which

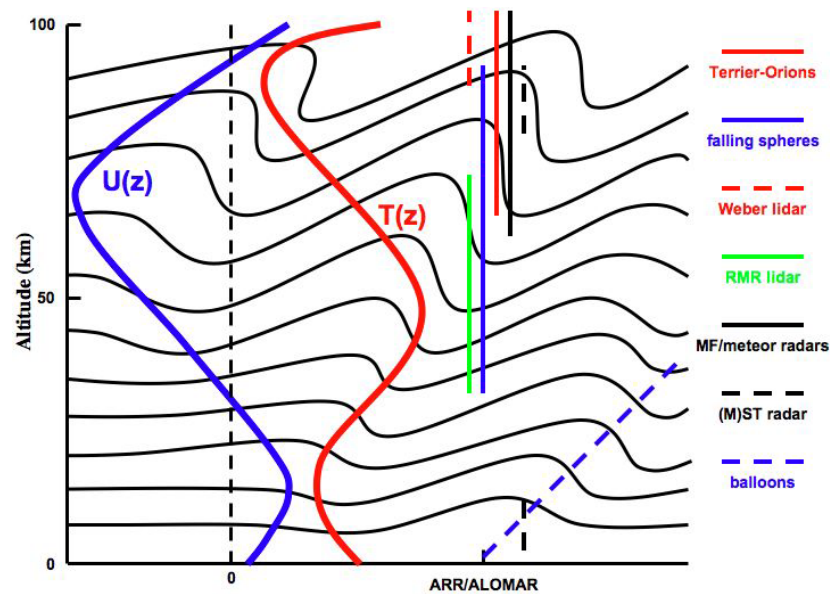

Fig. 1. Artist's representation of the MaCWAVE summer program. The WEBER lidar refers to the Na lidar at ALOMAR.

also observed neutral turbulence and temperature structure to higher altitudes, and with finer altitude resolution and precision at the higher altitudes than was possible with the FS. Figure 2 illustrates the sequences of rocket launches in summer 2002. Radiosondes were launched approximately once every two hours during each sequence. Several FS were also coordinated with TIMED satellite overpasses to permit comparison with temperatures determined by the SABER (Sounding of the Atmosphere using Broadband Emission Radiometry) instrument (Mertens et al., 2004). ALOMAR (von Zahn et al., 1995) lidar and radar data provided continuous ground-based measurements during the campaign.

This section reviews the MaCWAVE Terrier-Orion payloads (e.g. Goldberg et al., 2003, 2004). The MIDAS payloads and results are discussed elsewhere (e.g. Blix et al., 2003). Figure 3 is a schematic of the Terrier-Orion payload. It was designed in a symmetric configuration to permit similar ram and wake data acquisition during both up- and downleg. The relatively simple design enabled the Langmuir probes to function with maximum precision and sensitivity. During upleg, both the ram and wake probes were used to measure electrons and negative ions. During downleg, the polarity of the voltage on the leading probe was switched to measure positive ions. The blunt probes were biased positively and negatively, to provide information about nanometer sized particles expected to occur in any PMSE (polar mesospheric summer echo) events that might be encountered (Croskey et al., 2004; Mitchell et al., 2001). The Faraday rotation experiment is a radio propagation technique capable of measuring electron density $\left(N_{e}\right)$ more accurately than the Langmuir probes, but with much less resolution in space and time. By normalizing the Langmuir probe data to the Faraday-measured $N_{e}$ curves, it was possible to determine $N_{e}$ accurately with high spatial resolution. Four frequencies $(1.300,2.200,3.883$, and $7.835 \mathrm{MHz})$ enabled $N_{e}$ to be sampled from $60-\mathrm{km}$ altitude to apogee on each flight. 


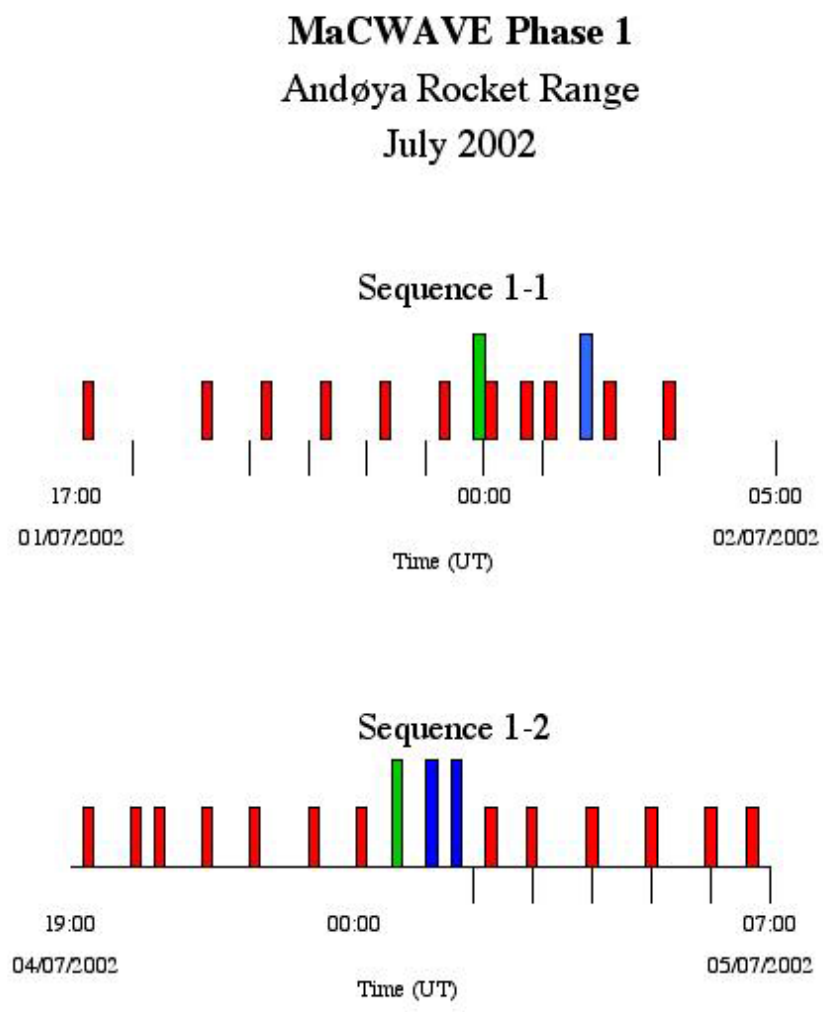

\section{MaCWAVE Terrier Orion \\ MIDAS Improved Orion \\ MET Falling Sphere}

Fig. 2. Summer rocket sequences.

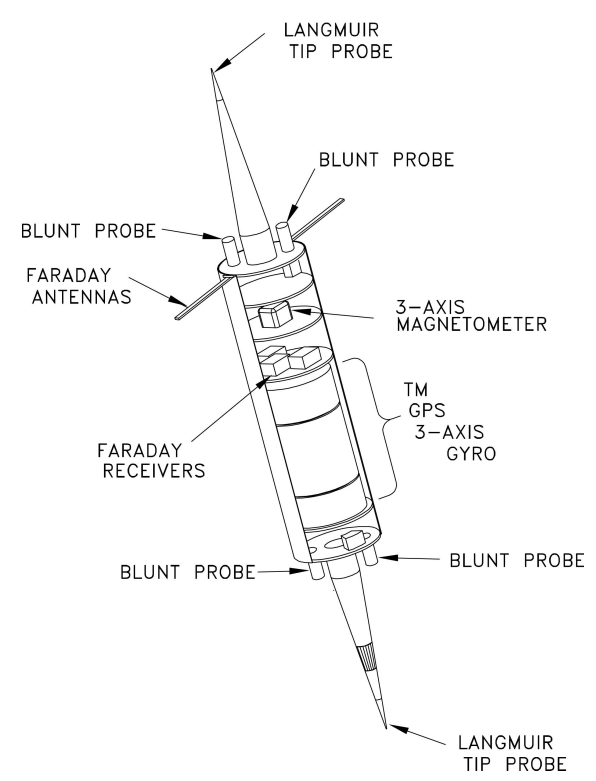

Fig. 3. MaCWAVE payload schematic.
Table 1. MaCWAVE summer launch and rocket information.

\begin{tabular}{|c|c|c|}
\hline & $\begin{array}{c}\text { MaCWAVE } \\
41.032\end{array}$ & $\begin{array}{c}\text { MaCWAVE } \\
41.033\end{array}$ \\
\hline Launch: Date (UT) & $01 / 07 / 2002$ & 05/07/2002 \\
\hline Time (UT) & 23:56:00 & $00: 47: 00$ \\
\hline Solar Zenith Angle (degrees) & 87.2 & 85.9 \\
\hline Solar Activity (Jy) & 148.0 & 142.6 \\
\hline Azimuth (degrees) & 328.2 & 332.3 \\
\hline Elevation (degrees) & 85.0 & 84.4 \\
\hline Time Since Launch at Apogee (sec) & 181.0 & 182.5 \\
\hline Height at Apogee $(\mathrm{km})$ & 129.6 & 132.4 \\
\hline Horizontal Range at $80 \mathrm{~km}$ upleg $(\mathrm{km})$ & 12.5 & 13.6 \\
\hline Horizontal range at Apogee $(\mathrm{km})$ & 32.8 & 36.8 \\
\hline Horizontal range at $80 \mathrm{~km}$ downleg $(\mathrm{km})$ & 53.1 & 59.8 \\
\hline Weight of payload (kg) & \multicolumn{2}{|c|}{213.2} \\
\hline Length of payload (m) & \multicolumn{2}{|c|}{4.3} \\
\hline Launch Site: Name & \multicolumn{2}{|c|}{ Andøya, Norway (ARR) } \\
\hline Latitude & \multicolumn{2}{|c|}{$69.3^{\circ} \mathrm{N}$} \\
\hline Longitude & \multicolumn{2}{|c|}{$16.0^{\circ} \mathrm{E}$} \\
\hline Geomagnetic Latitude & \multicolumn{2}{|c|}{$67.0^{\circ} \mathrm{N}$} \\
\hline Geomagnetic Longitude & \multicolumn{2}{|c|}{$114.8^{\circ} \mathrm{E}$} \\
\hline Magnetic L (100 km) & \multicolumn{2}{|c|}{6.2} \\
\hline
\end{tabular}

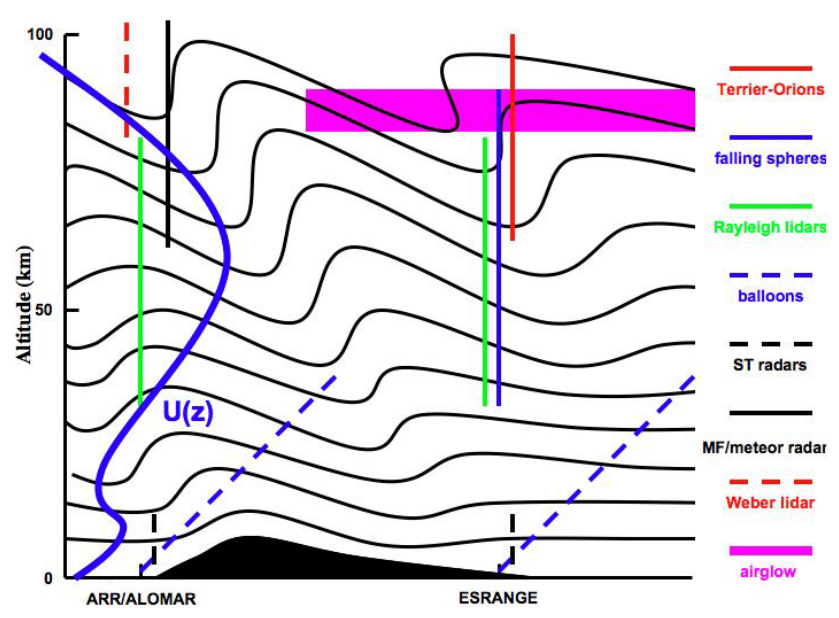

Fig. 4. Artist's representation of the MaCWAVE winter program. The WEBER lidar refers to the Na lidar at ALOMAR.

The summer and winter Terrier-Orion payloads were nearly identical in structure (see below), and all reached apogees between $125-130 \mathrm{~km}$. Table 1 lists the Andøya Rocket Range specifications and MaCWAVE flight characteristics for the summer program.

Figure 4 provides an artist's conception describing the winter MaCWAVE Program. As previously noted, the rocket flights were performed at Esrange to provide sensitivity to anticipated mountain wave structure in the lee of the Scandinavian mountains. Recent balloon and aircraft measurements reveal that mountain waves occur frequently in the lee of these mountains and often reach large amplitudes. It had been shown, based on the propagation model by Bacmeister et al. (1994), that northern Scandinavia is a preferred site for penetration of mountain waves into the MLT under winter 


\section{MaCWAVE Phase 2 \\ ESRANGE}

January 2003

Sequence 2-1

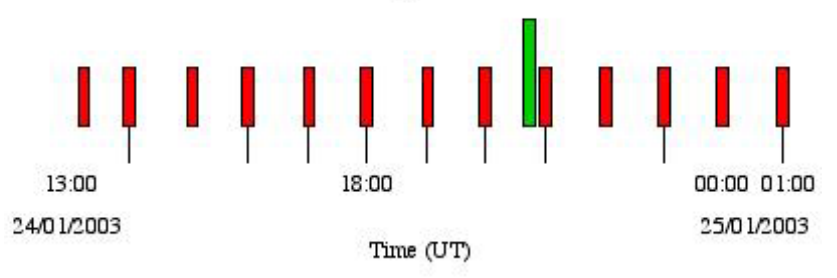

Sequence 2-2

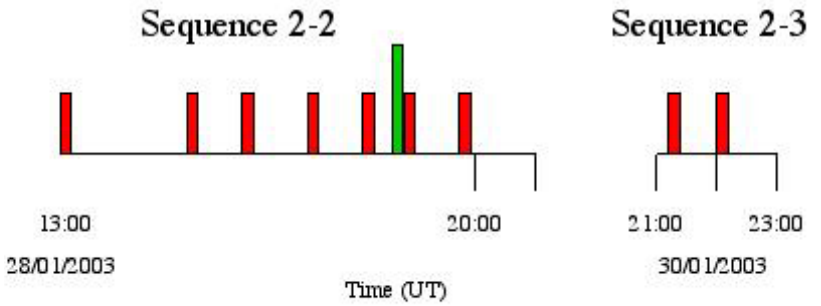

MaCWAVE Terrier Orion

MET Falling Sphere

Fig. 5. Winter rocket sequences.

Table 2. MaCWAVE winter launch and rocket information

\begin{tabular}{|c|c|c|}
\hline & $\begin{array}{c}\text { MaCWAVE } \\
41.030\end{array}$ & $\begin{array}{c}\text { MaCWAVE } \\
41.031\end{array}$ \\
\hline Launch: Date (UT) & $24 / 01 / 2003$ & $28 / 01 / 2003$ \\
\hline Time (UT) & $20: 50: 00$ & 18:32:00 \\
\hline Solar Activity (Jy) & 129.4 & 125.6 \\
\hline Solar Zenith Angle (deg) & 127.9 & 116.1 \\
\hline Azimuth (degrees) & 10.0 & 353.0 \\
\hline Elevation (degrees) & 82.4 & 84.0 \\
\hline Time Since Launch at Apogee (sec) & 181.5 & 181.0 \\
\hline Height at Apogee $(\mathrm{km})$ & 131.2 & 130.0 \\
\hline Horizontal Range at $80 \mathrm{~km}$ upleg $(\mathrm{km})$ & 13.4 & 16.4 \\
\hline Horizontal range at Apogee $(\mathrm{km})$ & 35.8 & 43.9 \\
\hline Horizontal range at $80 \mathrm{~km}$ downleg $(\mathrm{km})$ & 57.9 & 71.1 \\
\hline Weight of payload (kg) & \multicolumn{2}{|c|}{231.3} \\
\hline Length of payload (m) & \multicolumn{2}{|c|}{4.3} \\
\hline Launch Site: Name & \multicolumn{2}{|c|}{ Kiruna, Sweden (Esrange) } \\
\hline Latitude & \multicolumn{2}{|c|}{$67.9^{\circ} \mathrm{N}$} \\
\hline Longitude & \multicolumn{2}{|c|}{$21.0^{\circ} \mathrm{E}$} \\
\hline Geomagnetic Latitude & \multicolumn{2}{|c|}{$64.3^{\circ} \mathrm{N}$} \\
\hline Geomagnetic Longitude & \multicolumn{2}{|c|}{$104.1^{\circ} \mathrm{E}$} \\
\hline Magnetic L (100 km) & \multicolumn{2}{|c|}{5.5} \\
\hline
\end{tabular}
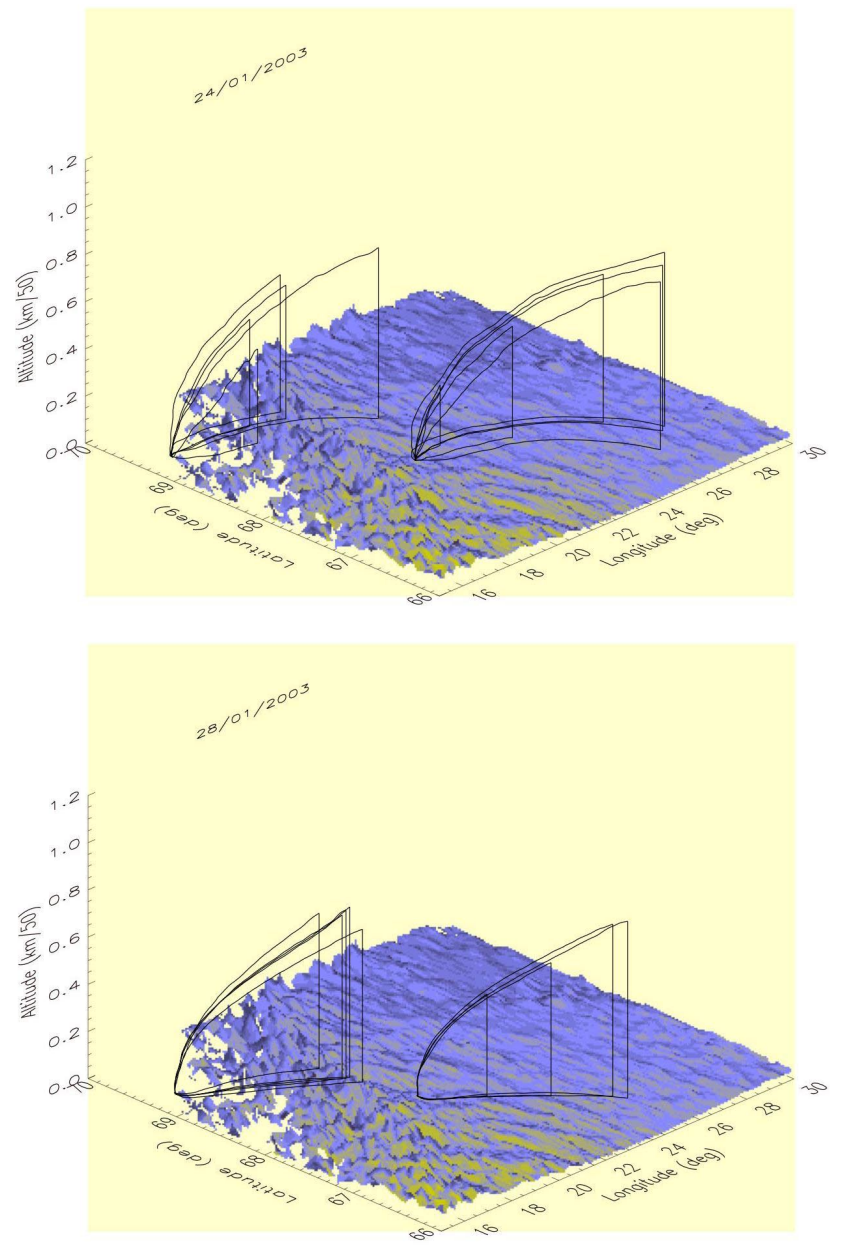

Fig. 6. 3-D flight trajectories of the radiosonde balloons launched during winter for 24 January (top) and 28 January 2003 (bottom) flight sequences. Scales are longitude, latitude and altitude, where altitude refers to the trajectory. The vertical scale of the terrain has been expanded to make it visible on the plot. Balloon tracks from both Andøya and Esrange are shown. Of note are the nearly identical patterns from each site, demonstrating the large-scale uniformity of the winds observed.

conditions. Indeed, this location has hosted several mountain wave measurement programs focused on ozone processing by stratospheric clouds enhanced by mountain wave structure.

The rocket measurements were augmented by balloon definition of wave structures at lower altitudes and ALOMAR and Esrange radar, lidar, and other related optical measurements of wave propagation, transports, and effects throughout the full depth of the atmosphere. The winter program included rocket sequences in late January 2003, with similar spacing to those in the summer program, as depicted in Fig. 5. The short sequence $2-3$ was intended for direct coordination with a TIMED overflight. 


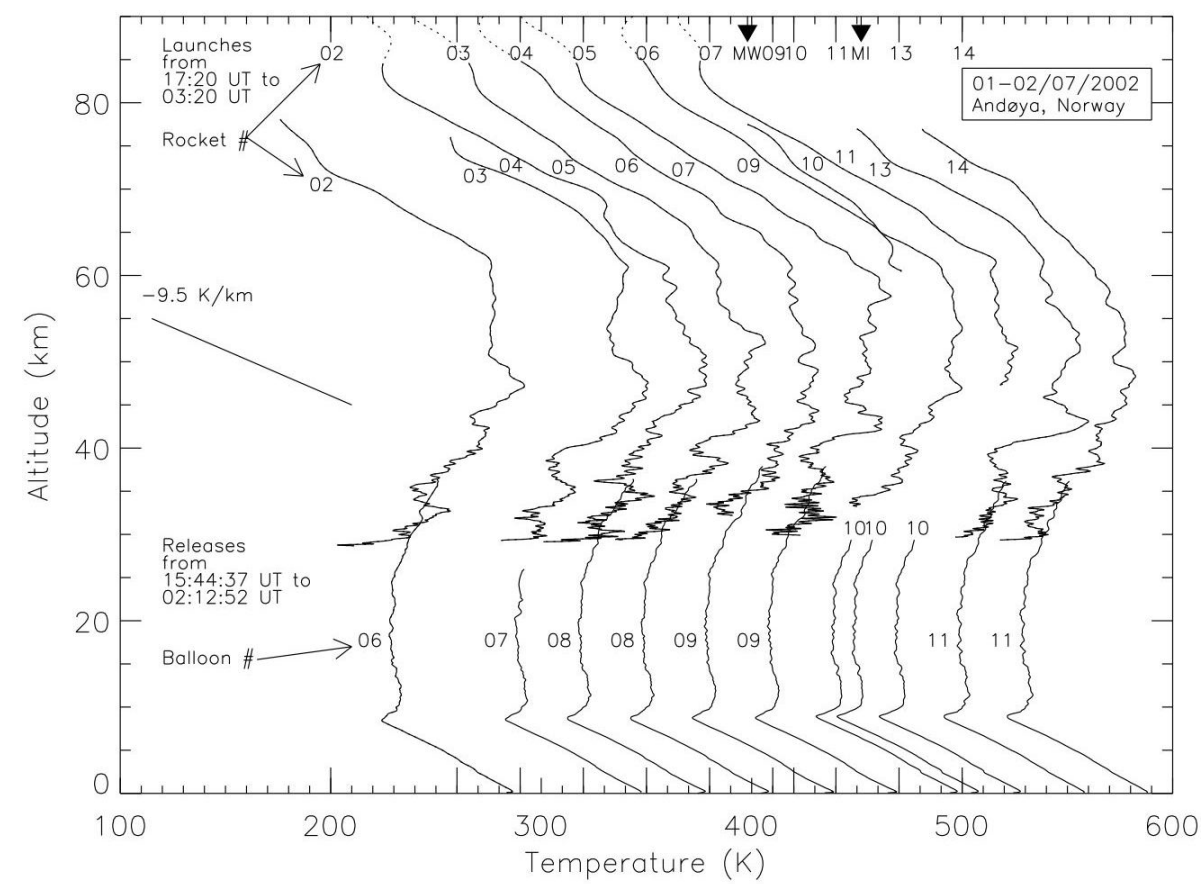

Fig. 7. Waterfall plot of the vertical temperature profiles measured by each rocket and balloon flight launched in the 1-2 July 2002 sequence at ARR and listed in Table 3. Each temperature profile is offset proportionally to the time between FS launches. The closest balloon measurement in time is matched with each rocket flight. The time for the MaCWAVE and MIDAS launches is indicated at the top. The profiles are dotted above $85 \mathrm{~km}$ where the accuracy rapidly degrades. Note that the temperatures at the lowest altitudes for the falling spheres become distorted because of sphere collapse. This also applies to the profiles in Figs. 8, 13 and 14.

Table 2 provides the Esrange specifications and the winter MaCWAVE Terrier-Orion flight characteristics. Figure 6 depicts the flight trajectories for balloons launched on 24 January (top panel) and on 28 January (bottom panel), from both Andøya and Esrange. The trajectories have been scaled so that the vertical dimensions are highly compressed relative to the surface orography. Projections on the earth's surface and the end point of each trajectory (vertical line) are also marked. The radiosonde trajectories were very similar on each side of the Scandinavian mountains, suggesting a potential for mountain wave excitation during these times.

\section{Overview of results}

\subsection{Summer results}

Initial analyses of the summer MaCWAVE/MIDAS measurements were presented in a series of papers that appeared in the 28 December 2004 issue of the Geophysical Research Letters (GRL). For completeness in this overview, some of the results reported there are expanded upon here. Others are explored more fully in the following papers. As noted earlier, the summer component of the MaCWAVE program focused on gravity wave propagation, instability, and wave-wave and wave-mean flow interaction dynamics contributing to summer mesopause structure and variability. The MaCWAVE and MIDAS rockets concentrated on smallscale dynamical and microphysical processes near the summer mesopause. The merged program yielded a comprehensive data set comprising two $\sim 12$-h rocket salvos, including 25 small meteorological rocketsondes (falling sphere MET rockets) and 5 sounding rockets, ground-based lidar, radar, and balloon data, and coordinated overpasses of the TIMED satellite. We note that the MIDAS payloads were primarily concerned with the study of PMSE. We therefore launched on nights when strong PMSEs were in progress, in the interest of coordination and collaboration. However, because of the possibility that we might observe plasma turbulence related to gravity wave breaking in the vicinity of PMSEs, this was also within the scope of the MaCWAVE objectives.

Waterfall plots of temperature for each FS flight sequence on 1-2 July and 4 July are shown in Figs. 7 and 8, respectively. Both figures show temperature profiles measured by the FS rockets and the Andøya-launched radiosondes in the air at the same time. The profiles are shifted in proportion to their temporal spacing. The numbers labeling each rocket and balloon flight are identified in Table 3. The time for each MaCWAVE (MW) and MIDAS (MI) rocket is also indicated. We note that on both nights, the temperature profiles above $75-\mathrm{km}$ altitude approached an adiabatic lapse rate 


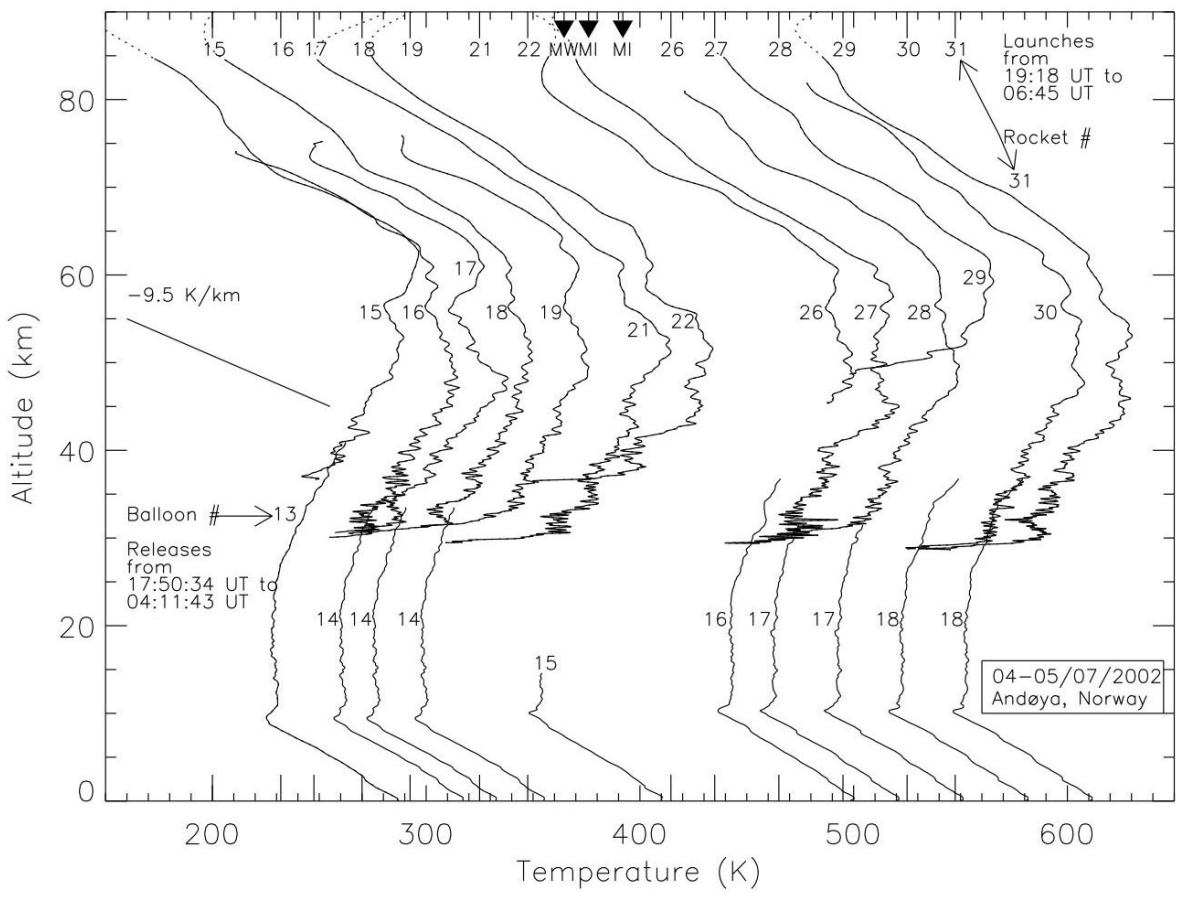

Fig. 8. Waterfall plot similar to Fig. 7, but for the July 4-5, 2002 sequence at ARR.

Table 3. Falling sphere and balloon information for Figs. 7 and 8. MIDAS/MaCWAVE Campaign July 2002, Andøya, Norway.

\begin{tabular}{|l|l|l|l|l|l|l|l|}
\hline Date (UT) & $\begin{array}{l}\text { Falling } \\
\text { sphere } \\
\text { range } \\
\text { designation }\end{array}$ & $\begin{array}{l}\text { Launch } \\
\text { time } \\
\text { (UT) }\end{array}$ & balloon & $\begin{array}{l}\text { Release } \\
\text { time (UT) }\end{array}$ & $\begin{array}{l}\text { Duration } \\
\text { of flight } \\
\text { (min) }\end{array}$ & $\begin{array}{l}\text { End } \\
\text { height } \\
\text { (km) }\end{array}$ & $\begin{array}{l}\text { End } \\
\text { time } \\
\text { (UT) }\end{array}$ \\
\hline $01 / 07 / 2002$ & mm-lfs-02 & $17: 20: 00$ & arr006 & $15: 44: 37$ & 137.62 & 36.4 & $18: 01$ \\
\hline $01 / 07 / 2002$ & mm-lfs-03 & $19: 20: 00$ & arr007 & $18: 20: 10$ & 83.47 & 26.0 & $19: 43$ \\
\hline $01 / 07 / 2002$ & mm-vfs-04 & $20: 20: 00$ & arr008 & $20: 17: 18$ & 121.79 & 36.4 & $22: 18$ \\
\hline $01 / 07 / 2002$ & mm-vfs-05 & $21: 20: 00$ & arr008 & $20: 17: 18$ & 121.79 & 36.4 & $22: 18$ \\
\hline $01 / 07 / 2002$ & mm-vfs-06 & $22: 20: 00$ & arr009 & $21: 57: 21$ & 131.90 & 37.9 & $00: 08$ \\
\hline $01 / 07 / 2002$ & mm-vfs-07 & $23: 20: 00$ & arr009 & $21: 57: 21$ & 131.90 & 37.9 & $00: 08$ \\
\hline $02 / 07 / 2002$ & mm-vfs-09 & $00: 20: 00$ & arr010 & $00: 01: 42$ & 100.03 & 29.4 & $01: 41$ \\
\hline $02 / 07 / 2002$ & mm-lfs-10 & $00: 40: 00$ & arr010 & $00: 01: 42$ & 100.03 & 29.4 & $01: 41$ \\
\hline $02 / 07 / 2002$ & mm-vfs-11 & $01: 20: 00$ & arr010 & $00: 01: 42$ & 100.03 & 29.4 & $01: 41$ \\
\hline $02 / 07 / 2002$ & mm-lfs-13 & $02: 20: 00$ & arr011 & $02: 12: 52$ & 121.82 & 36.3 & $04: 13$ \\
\hline $02 / 07 / 2002$ & mm-lfs-14 & $03: 20: 00$ & arr011 & $02: 12: 52$ & 121.82 & 36.3 & $04: 13$ \\
\hline $04 / 07 / 2002$ & mm-lfs-15 & $19: 18: 00$ & arr013 & $17: 50: 34$ & 129.13 & 40.9 & $19: 59$ \\
\hline $04 / 07 / 2002$ & mm-vfs-16 & $20: 14: 00$ & arr014 & $20: 15: 33$ & 108.67 & 33.5 & $22: 03$ \\
\hline $04 / 07 / 2002$ & mm-lfs-17 & $20: 45: 00$ & arr014 & $20: 15: 33$ & 108.67 & 33.5 & $22: 03$ \\
\hline $04 / 07 / 2002$ & mm-vfs-18 & $21: 30: 00$ & arr014 & $20: 15: 33$ & 108.67 & 33.5 & $22: 03$ \\
\hline $04 / 07 / 2002$ & mm-lfs-19 & $22: 15: 00$ & none & & & & \\
\hline $04 / 07 / 2002$ & mm-vfs-21 & $23: 20: 00$ & arr015 & $22: 35: 27$ & 45.63 & 14.6 & $23: 20$ \\
\hline $05 / 07 / 2002$ & mm-vfs-22 & $00: 05: 00$ & none & & & & \\
\hline $05 / 07 / 2002$ & mm-vfs-26 & $02: 19: 00$ & arr016 & $00: 19: 28$ & 122.08 & 36.8 & $02: 21$ \\
\hline $05 / 07 / 2002$ & mm-vfs-27 & $03: 00: 00$ & arr017 & $02: 24: 51$ & 111.05 & 31.5 & $04: 15$ \\
\hline $05 / 07 / 2002$ & mm-lfs-28 & $04: 00: 00$ & arr017 & $02: 24: 51$ & 111.05 & 31.5 & $04: 15$ \\
\hline $05 / 07 / 2002$ & mm-lfs-29 & $05: 00: 00$ & arr018 & $04: 11: 42$ & 122.66 & 36.8 & $06: 13$ \\
\hline $05 / 07 / 2002$ & mm-lfs-30 & $06: 00: 00$ & arr018 & $04: 11: 42$ & 122.66 & 36.8 & $06: 13$ \\
\hline $05 / 07 / 2002$ & mm-vfs-31 & $06: 45: 00$ & none & & & & \\
\hline & & & & & & & \\
\hline
\end{tabular}




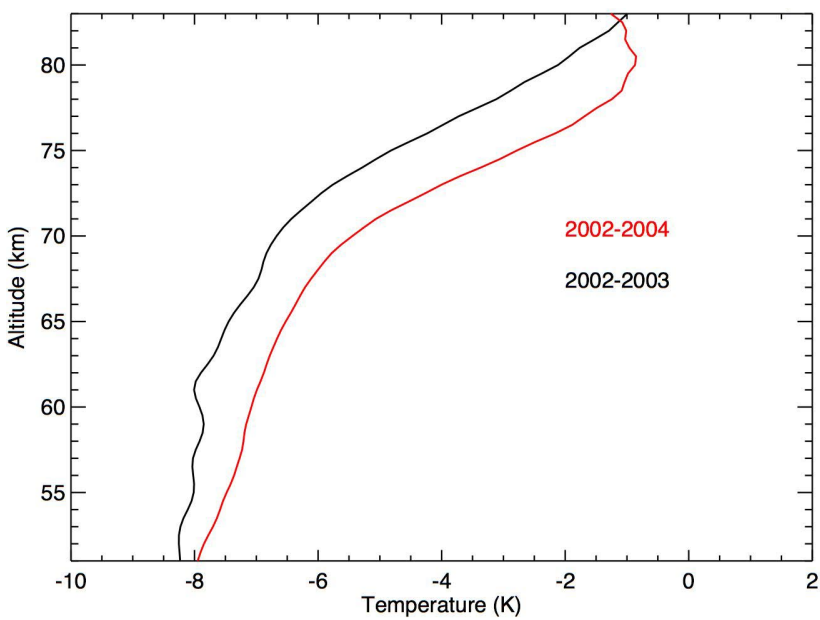

Fig. 9. Mean difference profiles of temperature measured by the SABER instrument aboard the TIMED satellite for 2002-2003 (black) and 2002-2004 (red) for the time period 15 June-15 July at $69-70^{\circ} \mathrm{N}$. Both demonstrate the cooler than normal atmosphere below $80 \mathrm{~km}$ during 2002 .

$(-9.5 \mathrm{~K} / \mathrm{km})$. This suggests that there was an unusual degree of gravity wave forcing. Evidence for unusually strong instability and turbulence activity was reported by Rapp et al. (2004) and Fritts et al. (2004). Departures from the normal mean temperatures in the MLT during summer 2002 are consistent with the turbulence results and the anomalous temperature measurements that were first summarized by Goldberg et al. (2004) and have also been seen in the SABER results discussed below.

As noted above, the GRL special section includes evidence for a lower and weaker residual (vertical and meridional) circulation during summer 2002, corresponding to a colder middle mesosphere and warmer mesopause, and a smaller occurrence frequency of PMSEs and noctilucent clouds (NLC) than under more typical summer conditions (Goldberg et al., 2004). Data obtained with the SABER instrument aboard the TIMED satellite, averaged from 15 June to 15 July and from 69 to $70^{\circ} \mathrm{N}$ for 2002, 2003, and 2004, show similar results. Figure 9 displays the temperature difference profiles for 2002-2003 and 2002-2004 from 51 to $83 \mathrm{~km}$ obtained from these data. In both cases, lower and middle mesosphere temperatures were colder in 2002, while the upper mesosphere was warmer, in agreement with summer MaCWAVE falling sphere measurements discussed above.

Earlier results also addressed other aspects of the largeand small-scale dynamics and microphysics under summer conditions. In several cases, they identified dynamics that appear to be unique to the summer 2002 environment. These include: 1) influences of Southern Hemisphere planetary wave activity on the Northern Hemisphere polar summer structure (Becker et al., 2004), 2) enhanced gravity wave amplitudes and gradients (Schöch et al., 2004; Williams et al., 2004;
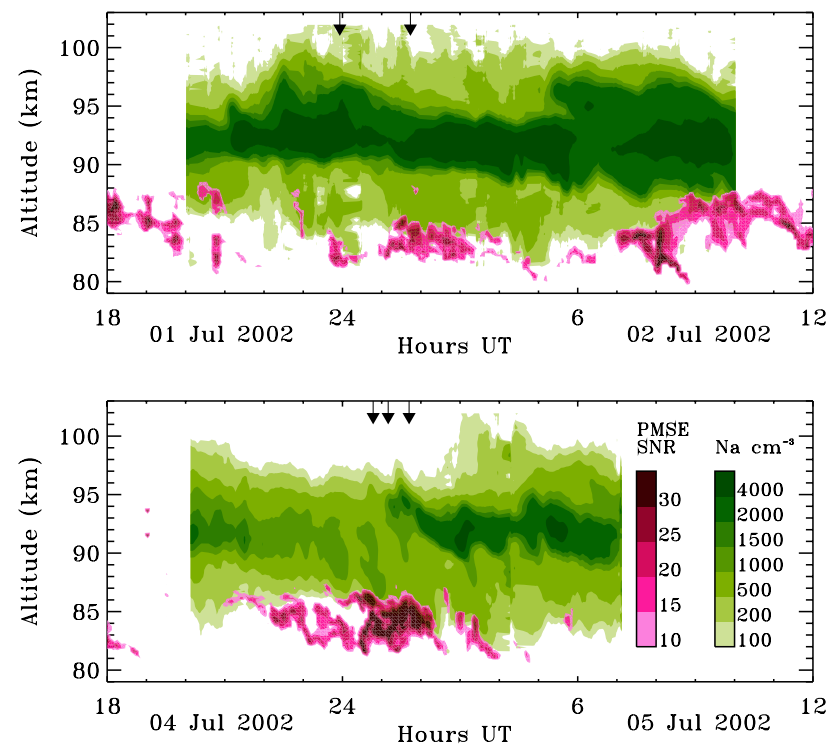

Fig. 10. The upper and lower panels show composite time-height contours of $\mathrm{Na}$ (green shading) and PMSE intensity during the two summer salvo periods. The MaCWAVE/MIDAS flight times are designated by arrows at the top of each panel. The $\mathrm{Na}$ and PMSE time-contours exhibit similar small-scale variability induced by gravity wave effects. Note the distinct cutoff between the bottom of the Na layer and the top of the PMSE layer in each panel.

Fritts et al., 2004), and 3) significantly increased turbulence intensities and occurrence in the upper mesosphere and lower thermosphere in both the neutral and plasma environment for both salvos (Rapp et al., 2004). A further study of the influences of Southern Hemisphere winter planetary wave activity on the Northern Hemisphere summer structure (Becker and Fritts, 2006) provides a more quantitative assessment of the dynamics underlying this apparent inter-hemispheric linkage.

Contours of sodium (Na) and PMSE echoes (SNR-ice particles) are shown for each summer salvo in Fig. 10. The MaCWAVE and MIDAS flight times during each salvo are shown at the top of each panel. The green contours in each panel relate exclusively to $\mathrm{Na}$, whereas the red contours relate exclusively to the PMSE intensities. Both sets of curves are seen to exhibit significant small-scale wave structure, albeit at different altitudes. In fact there is a sharp cutoff between the PMSE and SNR contours, also noted by She et al. (2006). It is clear from this figure that the MLT was extremely active with relatively small-scale wave structure during each of the two sequences. The MIDAS turbulence measurements provided values for energy dissipation above $82 \mathrm{~km}$ that exceeded values determined in earlier years. Furthermore, they also produced the first evidence for summertime neutral turbulence down to $70 \mathrm{~km}$ (Rapp et al., 2004). This unexpected turbulence activity was closely related to the larger middle and upper mesospheric temperature 


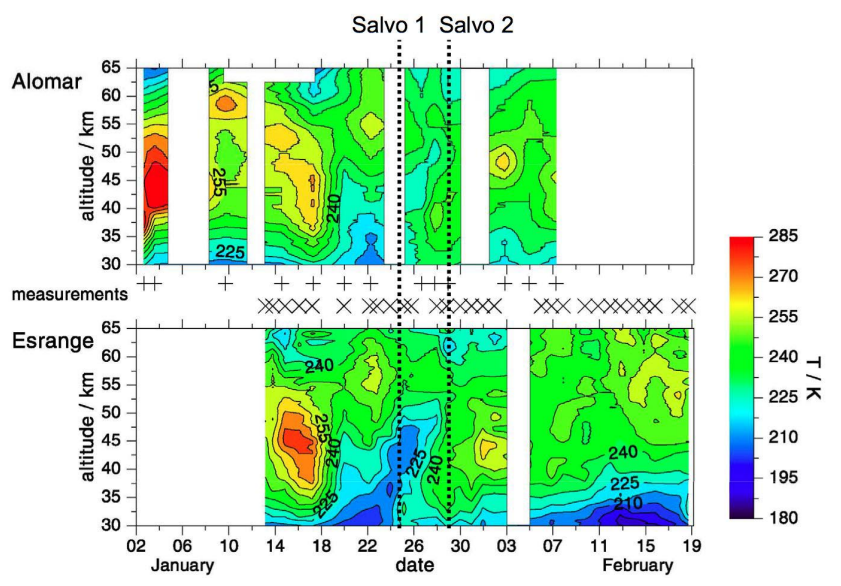

Fig. 11. RMR lidar soundings of temperature up to $65 \mathrm{~km}$ from ALOMAR and Esrange during the MaCWAVE winter period (after Blum et al., 2006). Measurement dates for the Alomar RMR lidar are marked with + signs, those of the Esrange RMR lidar with $\mathrm{X}$ signs. Both lidars show the onset of a stratospheric warming on about 15 January 2003.

gradients and enhanced gravity wave activity in that region (Williams et al, 2004; Fritts et al., 2004). We note that the neutral turbulence below $80 \mathrm{~km}$ seen by Rapp et al. (2004) was not identified in the plasma environment. One explanation may lie in the 55-min time separation between the MaCWAVE and MIDAS measurements.

An additional finding in the plasma microphysics was addressed by Croskey et al. (2004). This relates to the opportunity to approximate neutral turbulence through observations of the fluctuations in $N_{e}$. It has been assumed for some time that within the mesosphere, fluctuations in electron density $\left(\Delta N_{e} / N_{e}\right)$ are comparable to similar variability in the neutral density, and can thereby be used as a proxy for neutral turbulence. Croskey et al. (2004) have compared the results obtained using the MaCWAVE Langmuir probes with those obtained for neutral turbulence aboard the MIDAS flights using the CONE instrument. They concluded that the proxy holds outside of the PMSE zone in regions where plasma turbulence is observable ( $>$ about $80 \mathrm{~km}$ ), but only where few or no ice particles are present.

\subsection{Winter results}

As already noted, our anticipated winter objectives were impacted by the occurrence of a stratospheric warming just prior to the launch window in late January 2003. The RMR lidar profiles from ALOMAR and Esrange have been combined to produce Fig. 11 (after Blum et al., 2006). The onset of the warming at both sites was seen to occur by 15 January, with a very slow recovery following the event. The main effect of this warming was to induce a zonal wind shear near $65 \mathrm{~km}$ which is depicted for 24 January in Fig. 12. The shear exhibits a gradual progression downward throughout

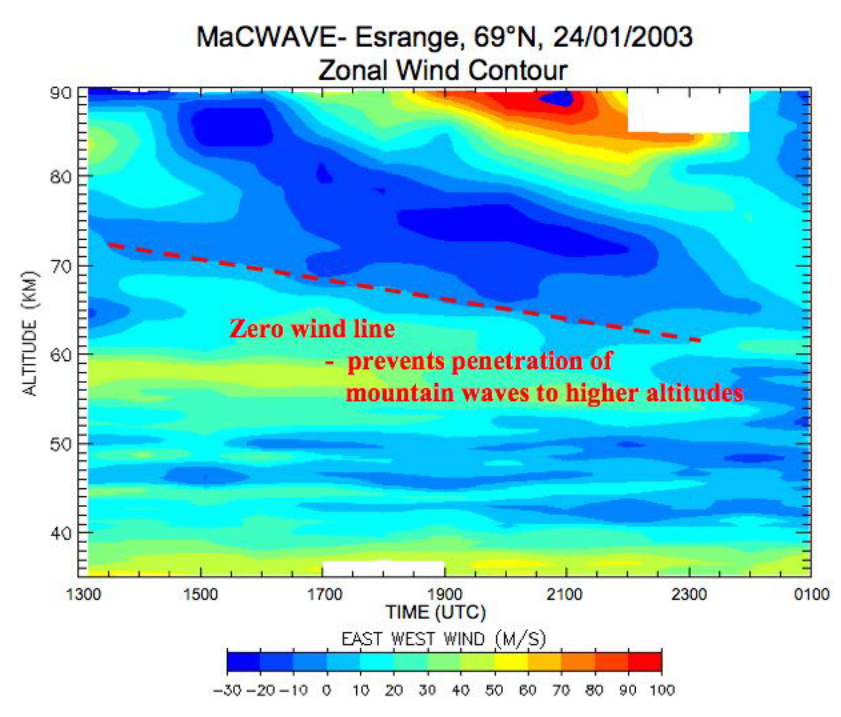

Fig. 12. Time contour of zonal winds on the night of 24 January 2003 (Salvo 1) during the MaCWAVE winter program as determined from the FS data. Eastward winds are positive. A wind reversal is seen to progress from $70 \mathrm{~km}$ down to $60 \mathrm{~km}$ during the night.

the night. This prevented penetration of mountain waves that likely arose due to the southeastward flow across the Scandinavian mountains to altitudes above the height of the shear, though gravity waves having other origins and phase speeds could still reach upper mesospheric altitudes. The figure exhibits significantly reduced wave amplitudes above the zero wind altitude. Measurements of the plasma fluctuations with the MaCWAVE rocket on this night also showed a smooth and normal profile with little evidence of turbulence at higher altitudes.

Figure 13 is a waterfall plot of the temperature profiles measured by the FS rockets and the ESRANGE-launched radiosondes throughout the atmosphere at the same time. The profiles are once again shifted in proportion to their temporal spacing. The numbers labeling each rocket and balloon flight are identified in Table 4. The increased wave activity below the zero wind altitude can also be identified in the temperature profiles and is addressed in detail by Wang et al. (2006). The wave activity above the wind shear was almost non-existent, as illustrated earlier in Fig. 12.

Conditions on the night of the second salvo on 28 January were strikingly different. Figure 14 provides a waterfall plot of the temperature profiles for 28 January 2003. Although the wave structure seen in the individual temperature profiles was much smoother at higher altitudes, the negative temperature gradient between $\sim 80$ and $85 \mathrm{~km}$ appeared to approach an adiabatic lapse rate with time. Watching this behavior with the FS measurements and the wave structure observed by the Na lidar and radars at ALOMAR, it seemed that a large-scale wave or superposition of waves might be tending 


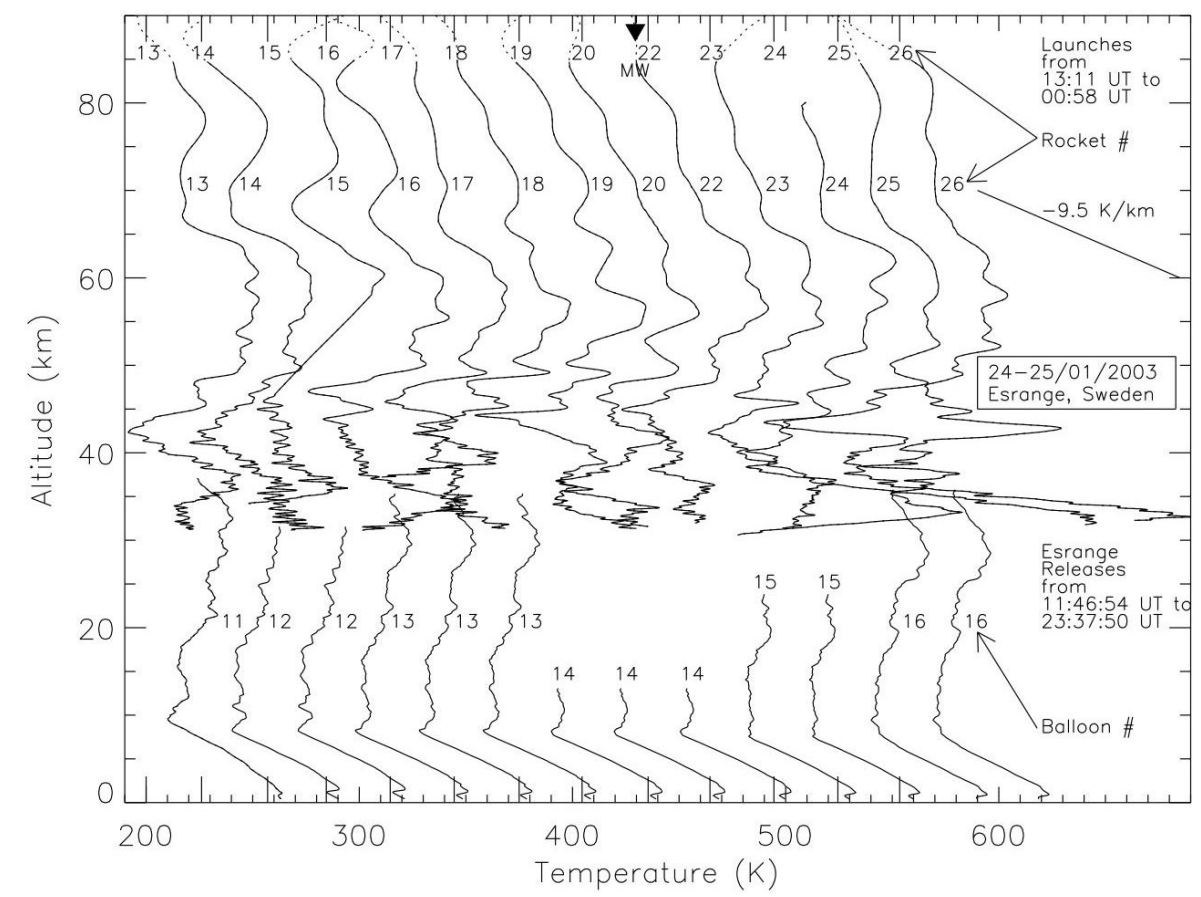

Fig. 13. Waterfall plot similar to Fig. 7, but for the 24-25 January 2003 sequence at Esrange.

Table 4. Falling sphere and balloon information for Figs. 13 and 14. MaCWAVE Campaign January 2003, Esrange, Kiruna, Sweden.

\begin{tabular}{|l|l|l|l|l|l|l|l|}
\hline Date (UT) & $\begin{array}{l}\text { Falling } \\
\text { sphere range } \\
\text { designation }\end{array}$ & $\begin{array}{l}\text { Launch } \\
\text { time (UT) }\end{array}$ & $\begin{array}{l}\text { Balloon } \\
\text { Esrange }\end{array}$ & $\begin{array}{l}\text { Release } \\
\text { time (UT) }\end{array}$ & $\begin{array}{l}\text { Duration } \\
\text { of flight } \\
\text { (min) }\end{array}$ & $\begin{array}{l}\text { End } \\
\text { height } \\
\text { (km) }\end{array}$ & $\begin{array}{l}\text { End time } \\
\text { (UT) }\end{array}$ \\
\hline $24 / 01 / 2003$ & ES03SL13 & $13: 11: 00$ & ES03RS11 & $11: 46: 54$ & 129.0 & 37.4 & $13: 55: 54$ \\
\hline $24 / 01 / 2003$ & ES03SL14 & $14: 03: 00$ & ES03RS12 & $13: 49: 35$ & 109.8 & 31.7 & $16: 26: 35$ \\
\hline $24 / 01 / 2003$ & ES03SL15 & $15: 05: 00$ & ES03RS12 & $13: 49: 35$ & 109.8 & 31.7 & $16: 26: 35$ \\
\hline $24 / 01 / 2003$ & ES03SL16 & $16: 00: 00$ & ES03RS13 & $16: 10: 54$ & 130.2 & 35.3 & $18: 32: 54$ \\
\hline $24 / 01 / 2003$ & ES03SL17 & $17: 00: 00$ & ES03RS13 & $16: 10: 54$ & 130.2 & 35.3 & $18: 32: 54$ \\
\hline $24 / 01 / 2003$ & ES03SL18 & $18: 00: 00$ & ES03RS13 & $16: 10: 54$ & 130.2 & 35.3 & $18: 32: 54$ \\
\hline $24 / 01 / 2003$ & ES03SL19 & $19: 01: 00$ & ES03RS14 & $19: 11: 47$ & 101.4 & 30.5 & $21: 16: 47$ \\
\hline $24 / 01 / 2003$ & ES03SL20 & $20: 00: 00$ & ES03RS14 & $19: 11: 47$ & 101.4 & 30.5 & $21: 16: 47$ \\
\hline $24 / 01 / 2003$ & ES03SL22 & $21: 02: 00$ & ES03RS14 & $19: 11: 47$ & 101.4 & 30.5 & $21: 16: 47$ \\
\hline $24 / 01 / 2003$ & ES03SL23 & $22: 00: 00$ & ES03RS15 & $22: 08: 52$ & 81.0 & 23.8 & $23: 29: 52$ \\
\hline $24 / 01 / 2003$ & ES03SL24 & $23: 00: 00$ & ES03RS15 & $22: 08: 52$ & 81.0 & 23.8 & $23: 29: 52$ \\
\hline $25 / 01 / 2003$ & ES03SL25 & $00: 00: 00$ & ES03RS16 & $23: 37: 50 *$ & 121.2 & 35.8 & $01: 50: 50$ \\
\hline $25 / 01 / 2003$ & ES03SL26 & $00: 58: 00$ & ES03RS16 & $23: 37: 50 *$ & 121.2 & 35.8 & $01: 50: 50$ \\
\hline $28 / 01 / 2003$ & ES03SL34 & $13: 00: 00$ & ES03RS22 & $11: 56: 07$ & 94.8 & 28.6 & $14: 18: 07$ \\
\hline $28 / 01 / 2003$ & ES03SL35 & $15: 04: 00$ & ES03RS23 & $13: 53: 50$ & 117.0 & 37.7 & $15: 50: 50$ \\
\hline $28 / 01 / 2003$ & ES03SL36 & $15: 57: 00$ & ES03RS24 & $15: 53: 51$ & 73.2 & 21.9 & $17: 18: 51$ \\
\hline $28 / 01 / 2003$ & ES03SL38 & $17: 05: 00$ & ES03RS24 & $15: 53: 51$ & 73.2 & 21.9 & $17: 18: 51$ \\
\hline $28 / 01 / 2003$ & ES03SL39 & $17: 57: 00$ & ES03RS25 & $17: 42: 40$ & 114.6 & 36.7 & $20: 12: 40$ \\
\hline $28 / 01 / 2003$ & ES03SL41 & $18: 42: 00$ & ES03RS25 & $17: 42: 40$ & 114.6 & 36.7 & $20: 12: 40$ \\
\hline $28 / 01 / 2003$ & ES03SL42 & $19: 42: 00$ & ES03RS25 & $17: 42: 40$ & 114.6 & 36.7 & $20: 12: 40$ \\
\hline$* 24 / 01 / 2003$ & & & & & & & \\
\hline
\end{tabular}

towards local instability at this altitude. The MaCWAVE rocket was launched at a time marked at the top of the figure, to match the time of maximum opportunity to observe the possibility of the wave breaking, should it occur.

This wave had a large spatial structure and was strongly modulating the MLT region at both sites simultaneously. Figure 15 shows contour plots of the wave structure in the temperature (left) and temperature difference (right) data, by combining the rocket FS, radar, and lidar results from both sites. The regions and times covered by each technique are indicated in the figure. It is apparent that a large-amplitude semidiurnal tide, perhaps with a large-scale gravity wave superposed, dominated the measurements during this period. If we view this wave with finer temporal resolution, we can 


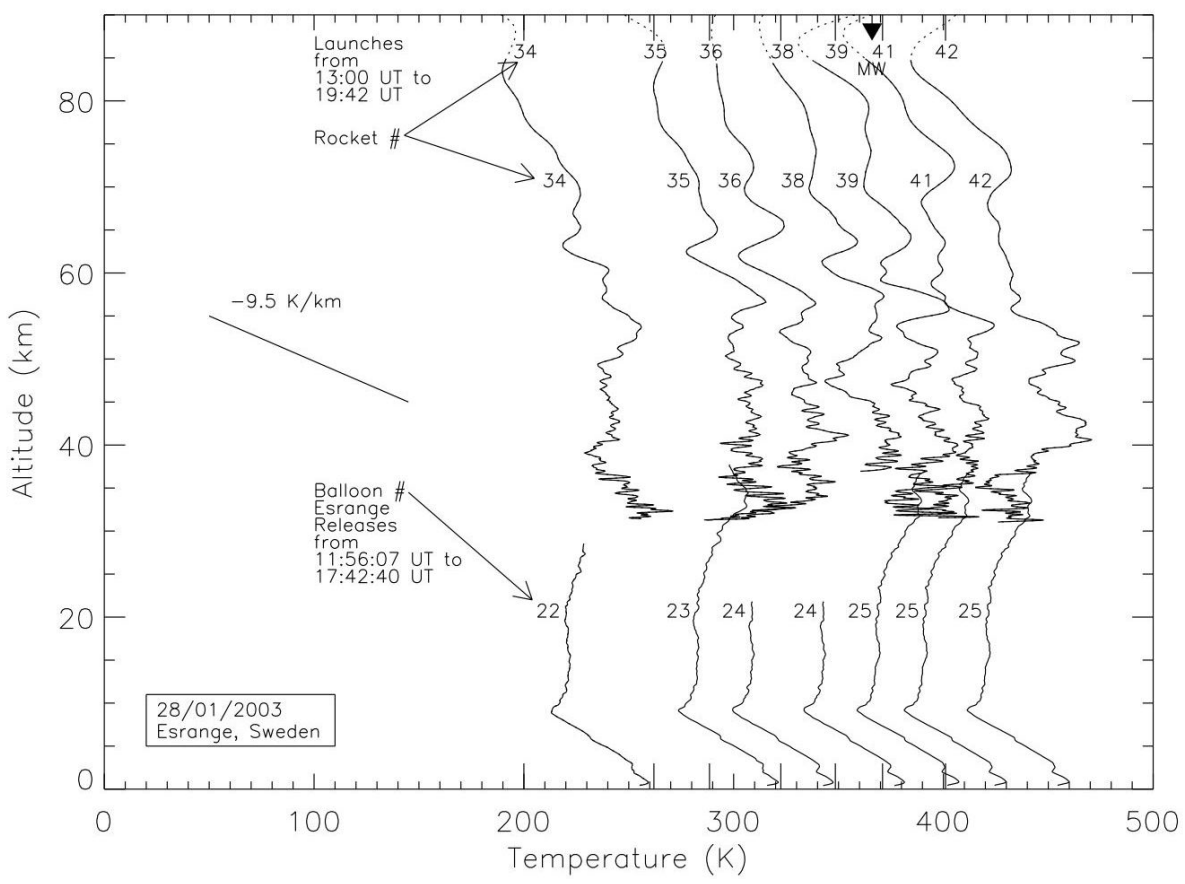

Fig. 14. Waterfall plot similar to Fig. 7, but for the 28 January 2003 sequence at Esrange.
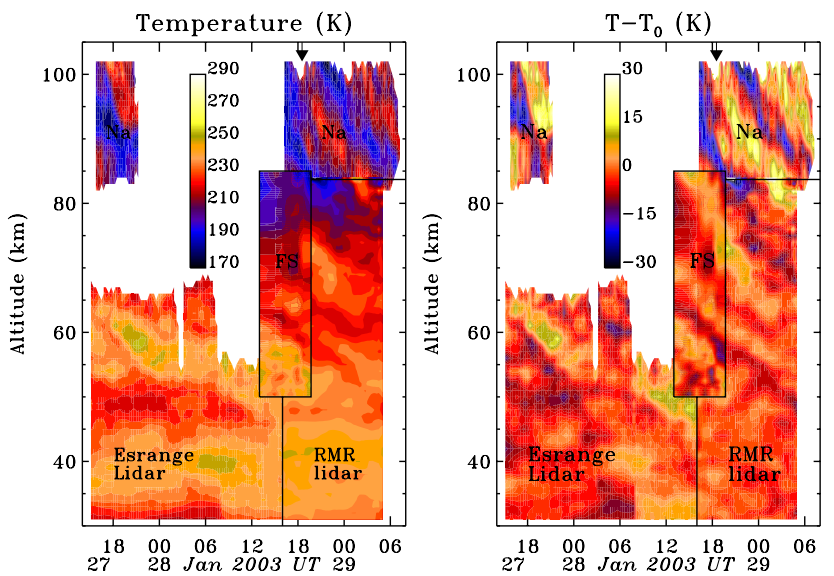

Fig. 15. A temperature (left) and temperature difference (right) map for 27-28 January 2003 as determined by combining RMR and $\mathrm{Na}$ lidar data at ARR with RMR lidar and FS data at Esrange. The blocks distinguish the regions where temperature is measured by each specified technique. In the right panel, $T_{o}$ indicates the mean temperature profile within the specified block. The small arrow at the top of each panel represents the launch of NASA 41.031 on 28 January 2003. The figure emphasizes the consistency between sites and large-scale of the planetary wave observed above $80 \mathrm{~km}$. The difference map also shows small-scale structure superimposed on the large wave.

observe several other contributions, suggesting an apparent wave period that decreases with altitude (see Williams et al., 2006a). Figure 16 displays a waterfall plot of the zonal wind

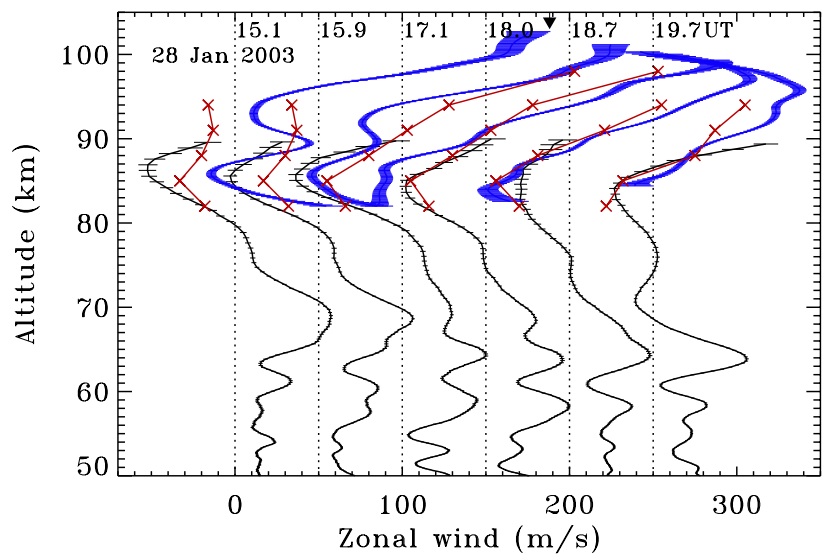

Fig. 16. Waterfall plot for 28 January 2003 of the zonal wind measured from the falling spheres (black), sodium lidar (blue), and meteor radar (red). The small arrow at the top of each figure represents the launch of NASA 41.031 on 28 January 2003.

structure on 28 January. This combines FS results (black) with the Andøya Na lidar (blue) and meteor radar (red) data. The large-scale wave was observed to progress throughout the measurement period with a downward phase propagation. In addition, there were small scale gravity waves seen up to $100 \mathrm{~km}$, most clearly in the first three profiles of the FS and Na lidar data. Potential mountain wave activity was seen at lower altitudes (see Wang et al., 2006). Further details of the magnitude and duration of the large-scale wave are seen 


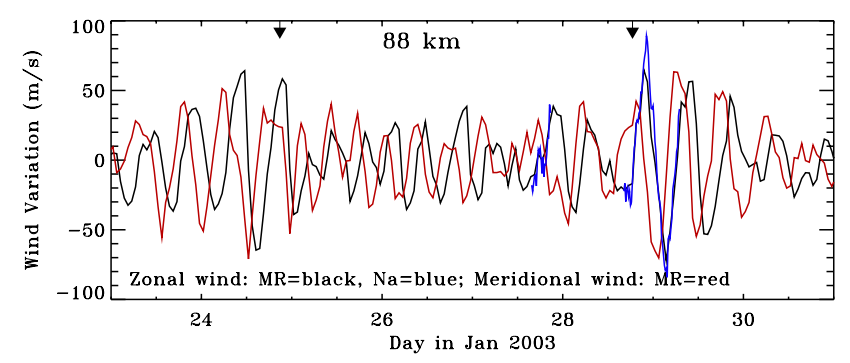

Fig. 17. ARR measurements of changes in the zonal wind at $88 \mathrm{~km}$ measured by the Na lidar (blue) and the meteor radar (MR, black), and of the meridional wind by MR (red) from 25-31 January 2003. The figure shows the strong amplification of the planetary wave on 28 January. Launch time of each winter MaCWAVE rocket is represented by the arrows at the top of the figure.

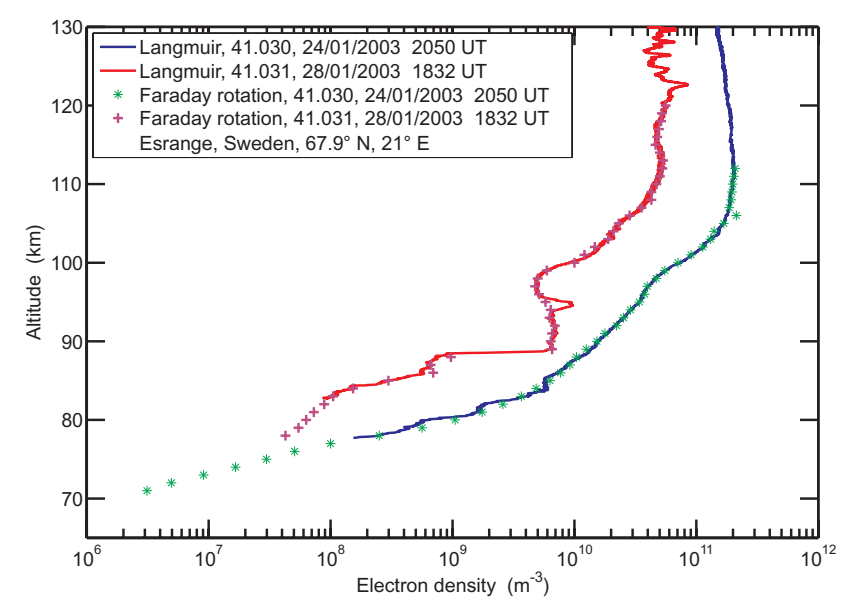

Fig. 18. Vertical profiles of electron density measured with the MaCWAVE rockets during the salvos on 24 January 2003 (blue) and 28 January 2003 (red). The absolute value of the detailed structure was obtained by normalizing the Langmuir probe currents to the radio propagation electron density profiles.

in the zonal and meridional winds displayed in Fig. 17. As noted, these represent measurements obtained from the Na lidar, MF radar, and meteor radar, all at ALOMAR. This wave arose shortly before our measurement interval, but reached an unusually large maximum on the night of our second salvo. The plot shows the wind variation, with a $24-\mathrm{h}$ running mean subtracted from the data. This shows the largeamplitude semidiurnal tide on 24 January, followed by an 8-h oscillation on 25-26 January, and the large semidiurnal amplitude on 27-29 January. Additional discussion of this wave structure and its variability is provided by Williams et al. (2006a).

Figure 18 compares the vertical profile of the electron density for 28 January with that on 24 January as measured by the MaCWAVE rockets. The observed structure was obtained

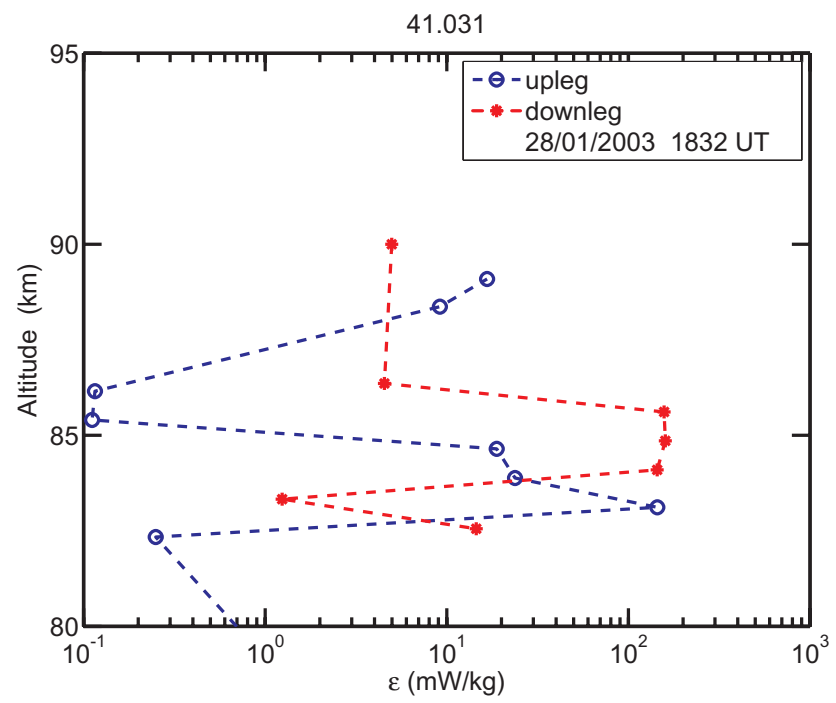

Fig. 19. Vertical profiles for the dissipation rate $(\varepsilon)$ during both upleg and downleg of MaCWAVE rocket flight NASA 41.031 on 28 January 2003 . Note the large increase near $85 \mathrm{~km}$ where wavebreaking was thought to occur.

by normalizing the Langmuir probe current to the electron density profile determined from the Faraday rotation experiment aboard the same MaCWAVE rocket. Our region of prime interest lies between $70-90-\mathrm{km}$ altitudes. On large scales, the profile on 24 January is more orderly and of higher magnitude, reflecting more magnetic activity $(\Sigma \mathrm{Kp}=26-)$ and energetic particle ionization on that night. On 28 January, the night was magnetically quiet locally, as seen by a local magnetogram, despite a value of $\Sigma \mathrm{Kp}=23$. However, the profile seems to have been perturbed by a wave structure not present on 24 January. This is consistent with the observations presented in Figs. 15-17. From $\Delta N_{e} / N_{e}$, one can determine the power spectral density curve for the $N_{e}$ turbulence fluctuations. As noted earlier, the conditions for treating this as a proxy for neutral atmospheric turbulence are reasonable during winter, because of the absence of ice-like aerosols. This spectrum of neutral density fluctuations can be seen in the charged species of the region, which serve as passive tracers of the neutral motion. The data analysis procedure involves identification of the scales associated with the buoyancy, inertial, and viscous subranges. Through determination of the "break" between the inertial and viscous subranges (e.g. the boundary between the $-5 / 3$ and -7 slopes), the energy dissipation rate can be determined using the FFT analysis approach (Goldberg et al., 1997; Lehmacher et al., 1997; Rapp et al., 2004; Croskey et al., 2004).

Figure 19 displays the calculated values for the energy dissipation rate, $\varepsilon$ during the MaCWAVE rocket measurement on the night of 28 January 2003. Both up- and downleg profiles of $\varepsilon$ are presented. As anticipated, the region near $85-\mathrm{km}$ altitude shows a major enhancement of 
energy dissipation, suggestive of wave-breaking induced by the large-scale and large-amplitude wave motions occurring at that time (Figs. 15-17). Values exceeding $100 \mathrm{~mW} / \mathrm{kg}$ are noted, which are extremely large for winter conditions, but compare quite well with the summer values seen for the neutral atmosphere between $\sim 80-90 \mathrm{~km}$ during the summer MaCWAVE/MIDAS campaign six months earlier (e.g. Rapp et al., 2004). Details of this analysis and more specific results are found in Croskey et al. (2006).

\section{Summary}

The MaCWAVE program was designed to investigate the influence of gravity waves on the MLT region under polar summer and winter conditions. The results for summer were obtained at the Andøya rocket range in Norway during July 2002 using two MaCWAVE and three MIDAS payloads, and numerous falling sphere and radiosonde soundings. Important collaborative measurements were obtained from the adjacent ALOMAR Observatory using lidar, radar, and other ground-based techniques. The results were also compared with SABER measurements from TIMED overflights that provided better characterization of the differences between seasonal means in different years. Major findings included the determination that the polar MLT during 2002 summer was unusual, exhibiting colder-than-normal temperatures below $80 \mathrm{~km}$, and warmer-than-normal temperatures near the mesopause and above. The effects of this anomalous polar summer included the appearance of fewer PMSEs and NLCs than normal (Goldberg et al., 2004), and more turbulence in the mid- to lower mesosphere Rapp et al. (2004). Becker et al. (2004) and Becker and Fritts (2006) have suggested a mechanism causing these anomalous summer conditions resulting from enhanced Rossby wave activity and the interhemispheric coupling that they induce.

Another result during summer came from a comparison between neutral (MIDAS) and plasma (MaCWAVE) atmospheric turbulence measurements, verifying that plasma turbulence is a good proxy for neutral turbulence, except in regions where small aerosols (ice or dust) are present, such as regions where PMSE's are observed (e.g. Croskey et al., 2006).

Turning to winter 2003, the launch program occurred at Esrange, Sweden, hoping to measure mountain waves generated by eastward flow over the Scandinavian orography. The plan was to track the mountain waves from lower altitudes into the mesosphere, where we expected that they would exhibit instability and wave-mean flow interactions. However, a major stratospheric warming occurred in mid-January (e.g. Blum et al., 2006), causing weak or reversed mean winds at altitudes above $\sim 50 \mathrm{~km}$. This wind environment blocked the penetration of mountain waves to mesospheric altitudes, as seen in the falling sphere data and described by Wang et al. (2006). However, a large-amplitude semidiurnal tide was observed near the mesopause, and appeared, in superposition with other motions, to result in local instability and turbulence comparable to summer mesopause intensities (see Williams et al., 2006a).

The papers that follow describe the results of our analyses of the summer MaCWAVE/MIDAS and winter MaCWAVE measurements in far greater detail than outlined here. These findings would not have been possible without the comprehensive suite of in situ and ground-based instruments assembled for these measurement campaigns.

Acknowledgements. We thank the Wallops Flight Facility team led by R. Weaver, and T. Wheeler of Pennsylvania State University, for their excellent support during payload design, testing, and launch activities. We also thank the ARR team led by K. Bøen and the Esrange team led by $\mathrm{S}$. Kemi for their invaluable support during launch activities, and P. Twigg and A. Beebe for valuable programming support and data analysis. The ALOMAR RMR lidar, the meteor radar, and the ALWIN VHF radar are all operated by IAP (Leibnitz Institute of Atmospheric Physics, Kühlungsborn, Germany). In addition, IAP has contributed significantly to measurements with the Weber sodium lidar through their installation and maintenance of the large mirrors that are shared by the RMR and Weber lidars and the focal boxes that IAP contributed to the facility. Support for this research was provided by NASA including contracts NAG501075, NAG5-5313, and NAS5-02036, by AFOSR under contracts F49620-00-C-0008 and F49620-03-C-0045, by NSF under grants ATM- 0137354 and ATM-0137555, by the German BMBF under DLR grants 50 OE 9802, 50 OE 9901, AFO-2000 grant 07ATF41 and 50EE0009, and by grant P15468 from the Austrian Research Fund. U. Blum is supported by the Marie-Curie Intra-European Fellowship Program of the European Community (MINERWA, No 010333). The authors thank the referees for their useful comments.

Topical Editor U.-P. Hoppe thanks two referees for their help in evaluating this paper.

\section{References}

Bacmeister, J. T., Newman, P. A., Gary, B. L., and Chan, K. R.: An algorithm for forecasting mountain wave-related turbulence in the stratosphere, Wea. Forecasting, 9, 241-253, 1994.

Becker, E. and Fritts, D. C.: Enhanced gravity-wave activity and interhemispheric coupling during the MaCWAVE/MIDAS northern summer program 2002, Ann. Geophys., 24, this issue, 2006.

Becker, E., Müllemann, A., Lübken, F.-J., Körnich, H., Hoffmann, P., and Rapp, M.: High Rossby-wave activity in austral winter 2002: Modulation of the general circulation of the MLT during the MaCWAVE/MIDAS northern summer program, Geophys. Res. Lett., 31, L24S03, doi:10.1029/2004GL019615, 2004.

Blix, T. A., Bekkeng, J. K., Latteck, R., Lübken, F.-J., Rapp, M., Schöch, A., Singer, W., Smiley, B., and Strelnikov, B.: Rocket probing of PMSE and NLC-results from the recent MIDAS/MACWAVE campaign, Adv. Space Res., 31(9), 20612067, 2003.

Blum, U., Baumgarten, G., Schöch, A., Kirkwood, S., Naujokat, B., and Fricke, K. H.: The meteorological background situation 
at polar latitudes during winter 2002/2003 in the context of the MaCWAVE campaign, Ann. Geophys., 24, this issue, 2006.

Broutman, D., Macaskill, C., McIntyre, M. E., and Rottman, J. W.: On Doppler-spreading models of internal waves, Geophys. Res. Lett., 24, 2813-2816, 1997.

Croskey C. L., Mitchell, J. D., Goldberg, R. A., Blix, T. A., Rapp, M., Latteck, R., Friedrich, M., and Smiley, B.: Coordinated investigation of particles and plasma/neutral density fluctuations during the MaCWAVE/MIDAS summer 2002 program, Geophys. Res. Lett., 31, L24S08, doi:10.1029/2004GL020169, 2004.

Croskey, C. L., Mitchell, J. D., Friedrich, M., Schmidlin, F. J., and Goldberg, R. A.: In situ electron and ion measurements and observed gravity wave effects in the polar mesosphere during the MaCWAVE program, Ann. Geophys., 24, this issue, 2006.

Dunkerton, T. J.: Stochastic parameterization of gravity wave stresses, J. Atmos. Sci., 39, 1711-1725, 1982.

Eckermann, S. D.: Influence of wave propagation on the Dopplerspreading of atmospheric gravity waves, J. Atmos. Sci., 54, 2544-2573, 1997.

Forbes, J. M., Gu, J., and Miyahara, S.: On the interactions between gravity waves and the diurnal propagating tide, Planet. Space Sci., 39, 1249-1257, 1991.

Fritts, D. C. and Alexander, M. J.: Gravity dynamics and effects in the middle atmosphere, Rev. Geophys., 41, doi:10.1029/2001RG000106, 2003.

Fritts, D. C. and Luo, Z.: Dynamical and radiative forcing of the summer mesopause circulation and thermal structure, 1 . Mean Solstice conditions, J. Geophys. Res., 100, 3119-3128, 1995.

Fritts, D. C. and Vincent, R. A.: Mesospheric momentum flux studies at Adelaide, Australia: Observations and a gravity wave/tidal interaction model, J. Atmos. Sci., 44, 605-619, 1987.

Fritts, D. C. and Yuan, L.: Measurement of momentum fluxes near the summer mesopause at Poker Flat, Alaska, J. Atmos. Sci., 46, 2569-2579, 1989.

Fritts, D. C., Williams, B. P., She, C. Y., Vance, J. D., Rapp, M., Lübken, F.-J., Müllemann, A., Schmidlin, F. J., and Goldberg, R. A.: Observations of extreme temperature and wind gradients near the summer mesopause during the MaCWAVE/MIDAS rocket campaign, Geophys. Res. Lett., 31, L24S06, doi:10.1029/2003GL019389, 2004.

Garcia, R. R.: Dynamics, radiation, and photochemistry in the mesosphere: Implications for the formation of noctilucent clouds, J. Geophys. Res., 94, 14 605-14 615, 1989.

Garcia, R. R. and Boville, B. A.: Downward control of the mean meridional circulation and temperature distribution of the polar winter stratosphere, J. Atmos. Sci., 51, 2238-2245, 1994.

Garcia, R. R. and Solomon, S.: The effect of breaking gravity waves on the dynamical and chemical composition of the mesosphere and lower thermosphere, J. Geophys. Res., 90, 3850-3868, 1985.

Goldberg, R. A. and Fritts, D. C.: Introduction to special section: The MaCWAVE-MIDAS Program to Study the Polar Summer Mesosphere, Geophys. Res. Lett., 31, L24S01, doi:10.1029/2004GL021789, 2004.

Goldberg, R. A., Lehmacher, G. A., Fritts, D. C., Mitchell, J. D., Friedrich, M., and Swartz, W. E.: Equatorial dynamics observed by rocket, radar, and satellite during the CADRE/MALTED campaign: 1: Programmatics and small scale fluctuations, J. Geophys. Res., 102, 26 179-26 190, 1997.
Goldberg, R. A., Fritts, D. C., Williams, B. P., Schmidlin, F. J., Croskey, C. L., Mitchell, J. D., Lübken, F.-J., Rapp, M., Singer, W., Latteck, R., Blix, T. A., Friedrich, M., Kirkwood, S., Mitchell, N., and Fricke, K. H.: The MaCWAVE Program to Study Gravity Wave Forcing of the Polar Mesosphere During Summer and Winter, Proceedings of the 16th ESA Symposium on European Rocket and Balloon Programmes and Related Research, St. Gallen, Switzerland, ESA SP-530, 345-350, 2003.

Goldberg, R. A., Fritts, D. C., Williams, B. P., Lübken, F.-J., Rapp, M., Singer, W., Latteck, R., Hoffmann, P., Müllemann, A., Baumgarten, G., Schmidlin, F. J., She, C.-Y., and Krueger, D. A.: The MaCWAVE/MIDAS rocket and groundbased measurements of polar summer dynamics: Overview and mean state structure, Geophys. Res. Lett., 31, L24S02, doi:10.1029/2004GL019411, 2004.

Haynes, P. H., Marks, C. J., McIntyre, M. E., Shephard, T. G., and Shine, K. P.: On the downward control of extratropical diabatic circulations by eddy-induced mean zonal forces, J. Atmos. Sci., 48, 657-678, 1991.

Holton, J. R.: The role of gravity wave-induced drag and diffusion in the momentum budget of the mesosphere, J. Atmos. Sci., 39, 791-799, 1982.

Holton, J. R.: The influence of gravity wave breaking on the general circulation of the middle atmosphere, J. Atmos. Sci., 40, 24972507, 1983.

Kirkwood, S., Belova, E., Blum, U., Croskey, C. L., Dalin, P., Fricke, K. H., Goldberg, R. A., Mitchell, J. D., and Schmidlin, F.: Polar mesosphere winter echoes during MaCWAVE, Ann. Geophys., 24, this issue, 2006.

Lehmacher, G. A., Goldberg, R. A., Schmidlin, F. J., Croskey, C. L., Mitchell, J. D., and Swartz, W. E.: Electron density fluctuations in the equatorial mesosphere: Neutral turbulence or plasma instabilities?, Geophys. Res. Lett., 24, 1715-1718, 1997.

Lu, W. and Fritts, D. C.: Spectral estimates of gravity wave energy and momentum fluxes, III: Gravity wave-Tidal interactions, J. Atmos. Sci. 50, 3714-3727, 1993.

Mayr, H. G., Mengel, J. G., Chan, K. L., and Porter, H. S.: Seasonal variations of the diurnal tide induced by gravity wave filtering, Geophys. Res. Lett., 25, 943-946, 1998.

McIntyre, M. E.: On dynamics and transport near the polar mesopause in summer, J. Geophys. Res., 94, 14617-14628, 1989.

McLandress, C. and Ward, W. E.: Tidal/gravity wave interactions and their influence on the large-scale dynamics of the middle atmosphere: Model results, J. Geophys. Res., 99, 8139-8156, 1994.

Mertens, C. J., Schmidlin, F. J., Goldberg, R. A., Remsberg, E. E., Pesnell, W. D., Russell III, J. M., Mlynczak, M. G., LopezPuertas, M., Wintersteiner, P. P., Picard, R. H., Winick, J. R., and Gordley, L. L.: SABER observations of mesospheric temperatures and comparisons with falling sphere measurements taken during the 2002 summer MaCWAVE Campaign, Geophys. Res. Lett., 31, L03105, doi:10.1029/2003GL018605, 2004.

Meyer, C. K.: Gravity wave interactions with the diurnal propagating tide, J. Geophys. Res., 104, 4223-4239, 1999a.

Meyer, C. K.: Gravity wave interactions with mesospheric planetary waves: A mechanism for penetration into the thermosphereionosphere system, J. Geophys. Res., 104, 28 181-28 196, 1999b. 
Mitchell, J. D., Croskey, C. L., and Goldberg, R. A.: Evidence for charged aerosols and associated meter-scale structure in identified PMSE/NLC regions, Geophys. Res. Lett., 28, 1423-1426, 2001.

Nastrom, G. D., Balsley, B. B., and Carter, D. A.: Mean meridional winds in the mid-and high-latitude summer mesosphere, Geophys. Res. Lett., 9, 139-142, 1982.

Nielsen, K., Taylor, M. J., Pautet, P. D., Mitchell, N., Beldon, C., Singer, W., Fritts, D. C., Schmidlin, F. J., and Goldberg, R. A.: Propagation and ducting of short-period gravity waves at high latitudes during the MaCWAVE winter campaign, Ann. Geophys., 24, this issue, 2006.

Norton, W. A. and Thuburn, J.: The two-day wave in a middle atmosphere GCM, Geophys. Res. Lett., 23, 2113-2116, 1996.

Rapp, M., Strelnikov, B., Müllemann, A., Lübken, F. J., and Fritts, D. C.: Turbulence measurements and implications for gravity wave dissipation during the MaCWAVE/MIDAS rocket program, Geophys. Res. Lett., 31, L24S07, doi:10.1029/2003GL019325, 2004.

Reid, I. M., Rüster, R., Czechowsky, P., and Schmidt, G.: VHF radar measurements of momentum flux in the summer polar mesosphere over Andenes ( $\left.69^{\circ} \mathrm{N}, 16^{\circ} \mathrm{E}\right)$, Norway, Geophys. Res. Lett., 15, 1263-1266, 1988.

Schöch, A., Baumgarten, G., Fritts, D. C., Hoffmann, P., Serafimovich, A., Wang, L., Dalin, P., Müllemann, A., and Schmidlin, F. J.: Gravity waves in the troposphere and stratosphere during the MaCWAVE/MIDAS summer rocket program, Geophys. Res. Lett., 31, L24S04, doi:10.1029/2004GL019837, 2004.

She, C. Y., Williams, B. P., Hoffmann, P., Latteck, R., Baumgarten, G., Vance, J. D., Fiedler, J., Acott, P., Fritts, D. C., and Lübken, F.-J.: Simultaneous observation of sodium atoms, NLC and PMSE in the summer mesopause region above ALOMAR, Norway (69N, 12E), J. Atmos. Solar-Terr. Phys., 68, 93-101, doi:10.1016/j.jastp.2005.08.014, 2006. von Zahn, U., Thrane, E. V., and Skatteboe, R.: The ALOMAR Facility: Status and Outlook, in Proceedings of the 12th ESA Symposium on European Rocket, and Balloon Programs and Related Research, Lillehammer, Norway, ESA SP-370, 379-385, 1995.

Wang, D.-Y. and Fritts, D. C.: Mesospheric momentum fluxes observed by the MST radar at Poker Flat, Alaska, J. Atmos. Sci., 47, 1511-1521, 1990.

Wang, L., Fritts, D. C., Williams, B. P., Goldberg, R. A., Schmidlin, F. J., and Blum, U.: Gravity waves in the middle atmosphere during the MaCWAVE winter campaign: evidence of mountain wave critical level encounters, Ann. Geophys., 24, this issue, 2006.

Williams, B. P., Fritts, D. C., Wang, L., She, C. Y., Vance, J. D., Schmidlin, F. J., Goldberg, R. A., Müllemann, A., and Lübken, F.-J.: Gravity waves in the Arctic mesosphere during the MaCWAVE/MIDAS summer rocket program, Geophys. Res. Lett., 31, L24S06, doi:10.1029/2004GL020049, 2004.

Williams, B. P., Fritts, D. C., She, C. Y., and Goldberg, R. A.: Gravity wave propagation through a large semidiurnal tide and instabilities in the mesosphere and lower thermosphere during the winter 2003 MaCWAVE rocket campaign, Ann. Geophys., 24, this issue, 2006a.

Williams, B. P., Croskey, C. L., She, C. Y., Mitchell, J. D., and Goldberg, R. A.: Sporadic sodium and E layers observed during the summer 2002 MaCWAVE/MIDAS rocket campaign, Ann. Geophys., 24, this issue, 2006b. 